\title{
Effects of changing milk replacer feedings from twice to once daily on Holstein calf innate immune responses before and after weaning ${ }^{1}$
}

\author{
L. E. Hulbert, ${ }^{\star} \dagger$ C. J. Cobb, ${ }^{*}$ J. A. Carroll, $†$ and M. A. Ballou* ${ }^{\star 2}$ \\ *Animal and Food Sciences, Texas Tech University, Lubbock 79409 \\ †USDA-ARS Livestock Issues Research Unit, Lubbock, TX 79403
}

\begin{abstract}
The objectives of this study were to determine the effects of switching Holstein calves to once-daily feeding during the fourth week of life $(24 \pm 2.3 \mathrm{~d}$ of age; once-fed $\mathrm{n}=22$; twice-fed $\mathrm{n}=22$ ) on innate immune responses, and to evaluate whether carry-over effects occurred when the calves were weaned during the seventh week of life. Peripheral blood samples were taken immediately before the change in feeding strategy (24 $\mathrm{d}$ of age) and at 27, 31, 45, 48, 52, and $66 \mathrm{~d}$ of age and were analyzed for circulating cortisol, haptoglobin, total leukocyte counts, neutrophil:mononuclear cells, and hematocrit percentage. Heparinized whole blood was also stimulated with lipopolysaccharide (LPS) for $24 \mathrm{~h}$ and the concentration of tumor necrosis factor- $\alpha$ $(\mathrm{TNF}-\alpha)$ in the supernatant was analyzed. Neutrophil L-selectin and $\beta_{2}$-integrin expression were analyzed by flow cytometry. Simultaneous neutrophil phagocytic and oxidative burst responses to a heat-killed Escherichia coli were quantified by dual-color flow-cytometry. Treatment (once-daily or twice daily feeding) had no effect on pre- or postweaning performance. Once-fed calves tended to have more circulating neutrophils at $27 \mathrm{~d}$ of age, greater expression of L-selectin on neutrophils at 31 and $45 \mathrm{~d}$ of age, and greater intensity of phagocytosis at $45 \mathrm{~d}$ of age. Once-fed calves secreted less TNF- $\alpha$ in LPS-stimulated whole blood cultures at $45 \mathrm{~d}$ of age compared with twice-fed calves and this tended to persist through the immediate postweaning period. None of the other immune parameters differed after weaning between the preweaning feeding strategies. Consolidating calf milk replacer into one feeding during the fourth week of life was likely a mild and acute stressor, as evidenced by transient neutrophilia in the absence of suppressed functional capacities of
\end{abstract}

Received November 2, 2010.

Accepted February 2, 2011.

${ }^{1}$ Mention of trade names or commercial products in this article is solely for the purpose of providing specific information and does not imply recommendation or endorsement by the US Department of Agriculture.

${ }^{2}$ Corresponding author: michael.ballou@ttu.edu neutrophils. Future research should address the mechanism and immunological significance of the persistent decreased $\mathrm{TNF}-\alpha$ response in once-fed calves.

Key words: feeding frequency, innate immunity, stress

\section{INTRODUCTION}

Feeding milk or milk replacer twice daily to dairy calves is labor intensive. A management strategy that decreases calf-rearing costs, due to reductions in time and labor, is to feed milk or milk replacer only once daily. Galton and Brakel (1976) reported a 39\% decrease in labor when calves were fed once daily versus twice daily. Moreover, calves fed once daily performed as well as calves fed twice daily. Feed intake, BW gain, body composition, feed efficiency, and morbidity did not differ between calves fed once versus twice daily (Ackerman et al., 1969; Galton and Brakel, 1976; Kehoe et al., 2007).

Changes in feeding strategies, including frequency and composition, can be perceived as a stressor by animals. This perceived stress could modulate the innate immune response, thereby decreasing the resistance to disease. No research has determined the influence of changing feeding frequency to once daily on the innate immune responses of preweaning dairy calves. Therefore, the objectives of this study were to determine the effects of switching Holstein calves to once-daily feeding during the fourth week of life on innate immune responses and to evaluate whether carry-over effects existed when the calves were weaned during the seventh week of life.

\section{MATERIALS AND METHODS}

The experiment was conducted from March to April 2010. All animal procedures were reviewed and approved by the Texas Tech University Animal Care and Use Committee. Forty-four Holstein bull calves (24 to $48 \mathrm{~h}$ after birth) were purchased from 2 local commercial dairies over a 7 -d period. Seventeen additional bull calves purchased from the same farms in the same period were also used in this study: these calves were weaned early (at $24 \pm 2.3 \mathrm{~d}$ of age) and used as bio- 
Table 1. Calf starter ingredient and chemical compositions

\begin{tabular}{lc}
\hline Item & Amount \\
\hline Ingredient, \% of DM & \\
Steam-flaked corn & 67.3 \\
Soybean meal, 48\% CP & 13.3 \\
Cottonseed meal & 11.3 \\
Molasses & 5.3 \\
Calf mineral/vitamin premix ${ }^{1}$ & 2.8 \\
Chemical composition & 88.2 \\
DM, \% & 18.9 \\
CP, \% & 3.06 \\
ME, Mcal/kg
\end{tabular}

${ }^{1}$ Premix contained (DM basis): $52.6 \%$ limestone; $39.9 \%$ soybean meal; $6 \%$ salt; $0.451 \%$ zinc sulfate; $0.4 \%$ selenium selenite $0.2 \% ; 0.267 \%$ manganese oxide; $0.18 \%$ vitamin E, $500 \mathrm{IU} / \mathrm{g} ; 0.157 \%$ copper sulfate; $142 \mathrm{mg} / \mathrm{kg}$ vitamin A, $1,000 \mathrm{kIU} / \mathrm{g} ; 12.5 \mathrm{mg} / \mathrm{kg}$ of ethylenediamine dihydroiodide; $8.7 \mathrm{mg} / \mathrm{kg}$ cobalt carbonate.

logical controls during the weaning stage of the experiment. All calves were fed $3.8 \mathrm{~L}$ of pooled first-milking colostrum from their respective dairy within $12 \mathrm{~h}$ of birth, and all calves were transported approximately $60 \mathrm{~km}$ to the Hilmar Cheese Calf Research Facility at Texas Tech University (New Deal, TX). Calves were housed with straw bedding in commercial polyethylene calf hutches (Agri-Plastics, Tonawanda, NY).

\section{Feeding and Weaning Strategies}

Before assignment to feeding strategy treatments, all calves were fed $227 \mathrm{~g}$, on an as-fed basis, of a $20 \%$ protein-20\% fat milk replacer (Herd Maker, Land O'Lakes Animal Protein Co., Shoreview, MN) in $2 \mathrm{~L}$ of water twice daily at 0800 and $1600 \mathrm{~h}$. After the first week, all calves were offered ad libitum access to a calf starter (Table 1) and water for the remainder of the study. The quantity of calf starter was adjusted daily for approximately $15 \%$ refusals. At $24 \pm 2.3 \mathrm{~d}$ of age, all calves $(47.6 \pm 4.1 \mathrm{~kg}$ of BW) were completely randomized to 1 of 2 feeding-strategy treatments: once-fed $(\mathrm{n}=22)$ or twice-fed $(\mathrm{n}=22)$. Beginning on this day, once-fed calves were given $454 \mathrm{~g}$, as fed, of the milk replacer in $4 \mathrm{~L}$ of water at the $0800 \mathrm{~h}$ feeding, whereas twice-fed calves had no changes to their original feeding regimen. Although previous research (Ackerman et al., 1969; Galton and Brakel, 1976) reported that dairy calves can be started on a once-daily feeding regimen at 3 $\mathrm{d}$ of age without influencing performance during the preweaning period compared with calves fed twice daily, we decided to first evaluate switching to the once-daily regimen during the wk 4 life because the risk of enteric disease is reduced at this age compared with during the first $3 \mathrm{wk}$ of life (Ballou and DePeters, 2008). Future research should determine whether switching to oncedaily feeding during the first week of life is stressful and suppresses innate immune responses.
Once-fed and twice-fed calves were all weaned 21 d after treatment enrollment (at $45 \pm 2.3 \mathrm{~d}$ of age). Early-weaned calves were weaned $21 \mathrm{~d}$ earlier $(24 \pm 2.3$ d of age). Weaning began by restricting the intake of milk replacer by $50 \%$. Twice-fed calves had their $1600 \mathrm{~h}$ milk replacer withdrawn, and once-fed calves had $50 \%$ of their milk replacer withdrawn at the $0800 \mathrm{~h}$ feeding to $227 \mathrm{~g}$ (as-fed basis). Calves were completely weaned when they consumed $900 \mathrm{~g}$ of calf starter (as-fed basis) for 2 consecutive days. Calves were individually weighed at arrival, and at $24,31,45,52$, and $66 \pm 2.3$ d of age.

\section{Blood Collection and Analyses}

Nine milliliters of peripheral blood was collected via jugular venipuncture immediately before assignment of treatments (age $24 \pm 2.3 \mathrm{~d}$ ), and at 27, 31, 45, 48, 52, and $66 \pm 2.3 \mathrm{~d}$ of age. Samples had to be collected into 2 blocks on 2 consecutive days to accommodate the logistics of running the immune function assays. The block (A or B) was assigned randomly to calves within their treatment $(\mathrm{n}=11$ twice-fed and $\mathrm{n}=11$ once-fed per block). Blood was collected into 2 evacuated blood collection tubes (6 and $3 \mathrm{~mL}$ ) containing heparin and immediately placed on ice. Within $1 \mathrm{~h}$ after collection, the $3-\mathrm{mL}$ Vacutainers from each calf were analyzed for hematocrit, total leukocyte counts, and differential analyses of neutrophils and mononuclear cells using a Cell Dyn 3700 with automated 50-sample loader and vet-package software (Abbott Laboratories, Abbott, IL). In addition, the neutrophil:mononuclear cell ratio (N:M) was calculated. Plasma was collected after a 15 -min centrifugation at $1,200 \times g$ and stored at $-80^{\circ} \mathrm{C}$ until analyzed for cortisol and haptoglobin concentrations. All plasma samples were analyzed in duplicate. Circulating concentrations of cortisol were determined using a commercially available competitive-binding Chemiluminescence-ELISA kit (Searchlight-Aushon BioSystems Inc., Billerica, MA). The intra- and interassay coefficients of variation were 5.8 and $7.2 \%$, respectively, for the cortisol assay. Plasma haptoglobin concentrations were determined by measuring haptoglobin/hemoglobin complex by the estimation of differences in peroxidase activity (Makimura and Suzuki, 1982; Arthington et al., 2003). Results were expressed in arbitrary units resulting from the absorption reading at $450 \mathrm{~nm} \times 100$. The intra- and interassay coefficients of variation were $1.8 \%$.

\section{Phagocytosis and Oxidative Burst Capacity of Neutrophils}

The simultaneous phagocytic (PG) and oxidative burst (OB) capacities of peripheral blood neutrophils 
in response to enteropathogenic Escherichia coli isolated from the spleen of a septicemic calf were analyzed. The E. coli were grown overnight in tryptic soy broth and quantified by serial dilution and spread plating on tryptic soy agar. The bacteria were heat-killed at $60^{\circ} \mathrm{C}$ for 30 min (killing was confirmed by spread plating on tryptic soy agar), washed, and resuspended at $10^{9} \mathrm{cfu} /$ $\mathrm{mL}$ and incubated for $2 \mathrm{~h}$ under constant agitation at room temperature with an equal volume of $100 \mu \mathrm{g} / \mathrm{mL}$ propidium iodide (Invitrogen, Carlsbad, CA). Killed, propidium iodide-labeled bacteria were washed twice and resuspended at $10^{9} \mathrm{cfu} / \mathrm{mL}$ in $1 \times$ PBS. Bacteria were aliquoted into $1-\mathrm{mL}$ volumes and stored at $-80^{\circ} \mathrm{C}$. Two hundred microliters of whole blood from the 6-mL Vacutainer per animal was incubated in an ice bath for $15 \mathrm{~min}$. Forty microliters of a $100 \mu M$ working concentration of dihydrorhodamine (Invitrogen) and the fluorescently labeled $E$. coli were added to each sample, vortexed thoroughly, and then placed in a $38.5^{\circ} \mathrm{C}$ water bath and incubated for $10 \mathrm{~min}$. After completion of incubation, the samples were immediately placed in an ice bath for 5 min to stop the reaction at a constant rate. Erythrocytes were hypotonically lysed and washed, and the leukocytes were analyzed by dualcolor flow cytometry using a Cell Lab Quanta SC flow cytometer (Beckman Coulter, Fullerton, CA). Using flow cytometer analysis software (QuantaSC MPL, Beckman Coulter), neutrophils were gated on the scatterplot of electric volume $\times$ side scatter. Neutrophils that were positive for both oxidative burst $(\mathrm{OB}+)$ and phagocytosis $(\mathrm{PG}+)$ were then gated using the FL-1 by FL-3 scatterplot. The $\mathrm{OB}+\mathrm{PG}+$ cell percentage and geometric mean fluorescence intensity of the FL-1 and FL-3 were analyzed for OB and PG, respectively. Flow cytometry compensation settings were determined using $E$. coli that were not fluorescently labeled with propidium iodide.

\section{Determination of Neutrophil Leukocyte Adhesion Molecules}

Two hundred microliters of whole blood from the 6-mL Vacutainer for each animal was incubated at a final dilution of $5 \mu \mathrm{g} / \mathrm{mL}$ of anti-bovine CD62L (monoclonal antibody IgG1-isotype made in mouse; VMRD, Pullman, WA) or $2.5 \mu \mathrm{g} / \mathrm{mL}$ of anti-bovine CD18 (the $\beta_{2}$-integrin chain of CD11a, b, and c heterodimers; monoclonal antibody IgG1-isotype made in mouse; VMRD) for $1 \mathrm{~h}$ in an ice bath. Erythrocytes were hypotonically lysed and then rinsed once. The leukocyte pellet was resuspended in fluorescein-labeled secondary antibody at a 1:400 dilution $\left[\mathrm{F}\left(\mathrm{ab}^{\prime}\right) 2\right.$ anti-mouse IgG:FITC; AbD Serotec Raleigh, NC]. Samples were incubated on ice for an additional $1 \mathrm{~h}$. Samples were then washed once using $1 \times$ PBS and then analyzed by single-color flow cytometry. Using the flow cytometer analysis software, neutrophils were gated on the scatterplot diagram of electric volume $\times$ side scatter. The total geometric mean fluorescence intensity (FL-1) for L-selectin or $\beta_{2}$-integrin was analyzed.

\section{LPS Stimulation of Whole Blood}

Whole blood was diluted 1:5 with RPMI 1640 (Invitrogen) containing 1\% antibiotics (Gibco AntibioticAntimycotic, Invitrogen). Whole blood was stimulated at a final concentration of $1 \mu \mathrm{g} / \mathrm{mL}$ of LPS $(E$. coli O111:B4; Sigma-Aldrich). Samples were incubated for $24 \mathrm{~h}$ in a humidified $5 \% \mathrm{CO}_{2}$ chamber. The cell culture plates were centrifuged for $10 \mathrm{~min}$ at $1,200 \times g$ at $4^{\circ} \mathrm{C}$. The supernatant fraction was collected and stored in a $-40^{\circ} \mathrm{C}$ freezer until analyzed for bovine TNF- $\alpha$ using a commercially available ELISA (DY2279E; R\&D Systems Minneapolis, MN). Standards were diluted in RPMI with $10 \%$ pooled bovine plasma and $1 \%$ antibiotics. The intra- and interassay coefficients of variation were 3.2 and $4.1 \%$, respectively, and the sensitivity of the assay was $125 \mathrm{pg} / \mathrm{mL}$.

\section{General Statistical Analysis}

All data were analyzed by REML ANOVA using the MIXED procedure of SAS (v.9.2, SAS Inst. Inc., Cary, NC). The ante-regressive (1) covariance structure for the within-subject measurement was used for all models. Repeated data were tested for normality of the residuals by evaluating the Shapiro-Wilk statistic using the UNIVARIATE procedure of SAS (v.9.2, SAS Inst. Inc.). Data that were not normally distributed were log-transformed before mixed model analysis. Pairwise differences were performed at each time using a slicedeffect multiple comparison approach with a TukeyKramer adjustment. Least squares means $( \pm$ SEM) are reported throughout. A treatment difference of $P \leq$ 0.05 was considered significant, and $P \leq 0.10$ was considered a tendency.

\section{Statistical Analysis for the Acute Effects of Once- Versus Twice-Daily Feeding}

Data to test the acute effects of once- versus twicedaily feeding included data from $24,27,31$, and $45 \pm$ $2.3 \mathrm{~d}$ of age. Baseline measurements taken immediately before assigning feeding strategy treatments (d 24) were tested as covariates in all statistical models. For this model, only the data from once-fed and twice-fed calves 
Table 2. Performance data for calves fed once or twice daily from d 24 to $45^{1}$

\begin{tabular}{lcccc}
\hline Item & Once & Twice & $\begin{array}{c}\text { Largest } \\
\text { SEM }\end{array}$ & $P$-value \\
\hline ADG, $\mathrm{kg} / \mathrm{d}$ & & & & \\
d 24 to 31 & 0.637 & 0.616 & 0.0596 & 0.802 \\
d 31 to 45 & 0.604 & 0.628 & 0.0275 & 0.530 \\
d 24 to 45 & 0.615 & 0.624 & 0.0218 & 0.764 \\
d 45 to 52 & 0.995 & 0.859 & 0.0629 & 0.131 \\
d 52 to 66 & 0.662 & 0.586 & 0.0522 & 0.300 \\
d 45 to 66 & 0.773 & 0.677 & 0.0420 & 0.109 \\
Starter intake, $\mathrm{kg}$ of DM & 12.1 & 12.3 & 0.61 & 0.789 \\
d 24 to 45 & 30.7 & 29.6 & 1.04 & 0.468 \\
d 45 to 66 & & & & \\
Feed:gain, $\mathrm{kg}$ of DM/kg of BW & 1.65 & 1.62 & 0.043 & 0.764 \\
d 24 to 45 & 2.06 & 2.31 & 0.115 & 0.132 \\
d 45 to 66 & & & & \\
\hline
\end{tabular}

${ }^{1}$ Calves were fed $227 \mathrm{~g}$ of milk replacer twice daily until $24 \pm 0.5 \mathrm{~d}$ of age. After $24 \mathrm{~d}$ of age, 22 calves (oncefed) had the evening milk feeding withdrawn and all $454 \mathrm{~g}$ of milk replacer was fed in the morning, whereas twice-fed calves $(\mathrm{n}=20)$ had no change in feeding strategy. All calves were weaned at $45 \mathrm{~d}$ of age.

were used. For all metabolic and immune response data, excluding data analyzed by flow cytometry, a linear mixed model with the fixed effects of treatment, time, and the interactions of treatment $\times$ time and block $\times$ treatment $x$ time was fitted. The random effect was calf tested within treatment $\times$ block.

Before statistically analyzing all the flow cytometry data, the data from the once-fed calves were divided by the block mean of the data from the twice-fed calves to account for daily variation resulting from flow cytometry settings. All flow cytometry data for the once-fed calves are presented as the percentage of twice-fed calf means. The fixed effects of time and the interaction of time $\times$ block were fitted. The random effect was calf nested within block.

\section{Statistical Analysis for Carry-Over Effects on Weaning}

Data that were used to test the carry-over effects of once-fed versus twice-fed on innate immune responses at weaning included measures from $45,48,52$, and 66 $\pm 2.3 \mathrm{~d}$ of age. For all metabolic and immune response data, excluding data analyzed by flow cytometry, a linear mixed model with the fixed effects of treatment, time, and the interactions of treatment $\times$ time and block $\times$ treatment $\times$ time was fitted. The random effect was calf tested within treatment $\times$ block.

Similarly to the acute-effect analysis, flow cytometry data from the once-fed and twice-fed calves were divided by the block mean from the control calf data (early-weaned calves) and are presented as the percentage of control calf means. The fixed effects were time and the interaction of time $\times$ block, and the random effect was calf nested within block.

\section{RESULTS}

\section{Performance}

Two twice-fed calves died and were removed before data analysis. No differences $(P<0.139$; Table 2$)$ in performance between once- and twice-fed calves were observed before or after implementing the feeding strategy. All calves consumed enough calf starter to have milk replacer completely removed at $2 \pm 0.8 \mathrm{~d}$ after the weaning process was initiated on $\mathrm{d} 45 \pm 2.3 \mathrm{~d}$ of age $(P>0.10)$.

\section{Acute Effects of Once- Versus Twice-Daily Milk Replacer}

No treatment or treatment $\times$ time effects were observed for peripheral total leukocyte counts, hematocrit percentages, cortisol concentrations, or haptoglobin concentrations. Among all calves, peripheral total leukocytes and cortisol concentrations were greater on 31 and $45 \mathrm{~d}$ of age $(P<0.01$; Table 3$)$. Plasma haptoglobin concentrations decreased with increasing age in all calves $(P<0.05$; Table 3$)$. At $27 \mathrm{~d}$ of age, N:M ratios tended (log-transformed $P=0.07$; Figure 1 ) to be greater among once-fed than twice-fed calves.

Concentrations of TNF- $\alpha$ from LPS-stimulated whole blood increased with increasing age $(P<0.01$; Table 3 ), and were lower from once-fed calves than twice-fed calves at $45 \mathrm{~d}$ of age $(P<0.05$; Figure 2$)$. A tendency $(P=0.07)$ was observed for neutrophils from once-fed calves to express more L-selectin on 31 and $45 \mathrm{~d}$ of age when compared with twice-fed calves (Table 4). No differences in neutrophil $\beta_{2}$-integrin expression or OB responses were observed between once-fed and twicefed calves; however, once-fed calves tended $(P=0.06)$ 


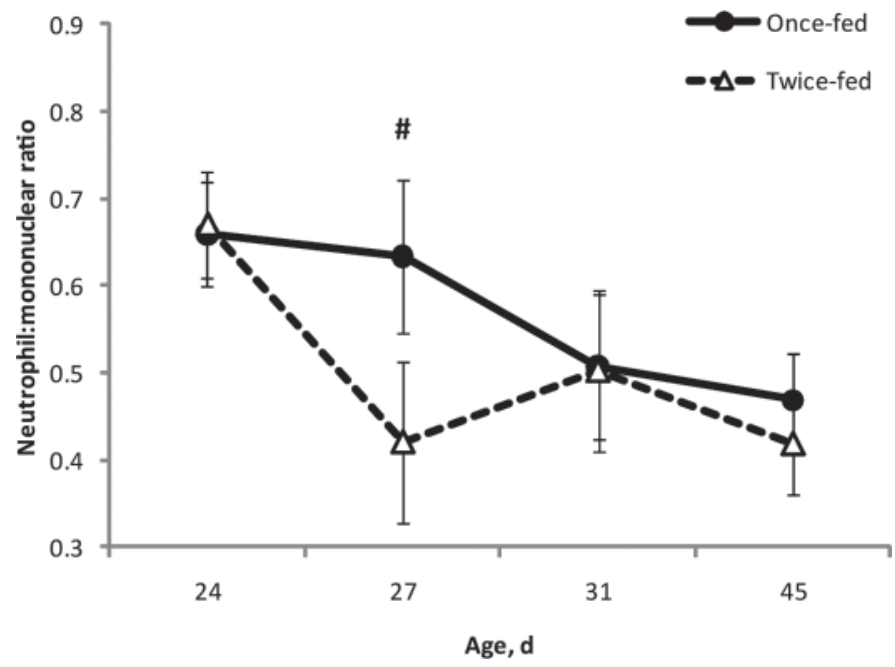

Figure 1. Acute effects on change in feeding frequency for neutrophil:mononuclear cell ratios for twice-fed and once-fed calves. Treatment $\times$ time sliced effect $\log$-transformed ${ }^{\#} P=0.10$. Calves were fed $227 \mathrm{~g}$ of milk replacer twice daily until $24 \pm 0.5 \mathrm{~d}$ of age. After 24 $\mathrm{d}$ of age, 22 calves (once-fed) had the evening milk feeding withdrawn and all $454 \mathrm{~g}$ of milk replacer was fed in the morning, whereas twicefed calves $(\mathrm{n}=20)$ had no change in feeding strategy.

to have greater neutrophil phagocytosis intensity at 45 d of age (Table 4).

\section{Previous Feeding Strategy Effects on Weaning}

No significant treatment or treatment $\times$ time effects were observed for peripheral total leukocyte count, N:M ratio, hematocrit percentage, cortisol concentration, or haptoglobin concentration. After weaning, all calves had decreased hematocrit $(P<0.01$; Table 5$)$ on 52 and $66 \mathrm{~d}$ of age. The N:M cell ratios were greater $(P<$ 0.05 ; Table 5) at $66 \mathrm{~d}$ of age compared with d 52 of age in all calves, whereas plasma haptoglobin concentrations $(P<0.01$; Table 5$)$ were decreased.

Twice-fed calves had greater $(P<0.05)$ TNF- $\alpha$ from LPS-stimulated whole blood compared with once-fed calves at d 45 of age, which was immediately before weaning (Figure 3 ). In addition, a treatment tendency $(P=0.09)$ was observed for once-fed calves to secrete less TNF- $\alpha$ than twice-fed calves during the postweaning period (Figure 3). All calves had decreased TNF- $\alpha$ concentrations in LPS-stimulated whole blood after weaning $(P<0.01$; Table 5$)$, but this was not likely associated with weaning because the early-weaned calves also had less TNF- $\alpha$ secreted from LPS-stimulated whole blood on that day.

No treatment $\times$ time or treatment effects were observed for neutrophil adhesion molecule expression between once-fed and twice-fed calves after weaning $(P$ $>0.10)$; however, all calves had increased $\beta_{2}$-integrin expression $3 \mathrm{~d}$ after weaning $(P<0.01$; Table 6$)$. In addition, all calves had a decrease in the percentage of neutrophils that produced both $\mathrm{OB}$ and $\mathrm{PG}$ as well as their intensities $3 \mathrm{~d}$ after weaning $(P<0.01$; Table 6$)$.

\section{DISCUSSION}

Consolidating milk replacer feedings into one feeding during wk 4 of life would decrease labor and subsequent calf-rearing costs; therefore, the objectives of this study were to determine the effects of switching Holstein calves to once-daily feeding during wk 4 of life on innate immune responses and to evaluate any carry-over effects when the calves were weaned during the seventh week of life. In agreement with other data (Ackerman et al., 1969; Galton and Brakel, 1976; Kehoe et al., 2007), no differences in performance were observed between

Table 3. Daily means of blood measurements of all calves $(n=42)$ after once-fed calves had milk replacer consolidated into 1 feeding ${ }^{1,2}$

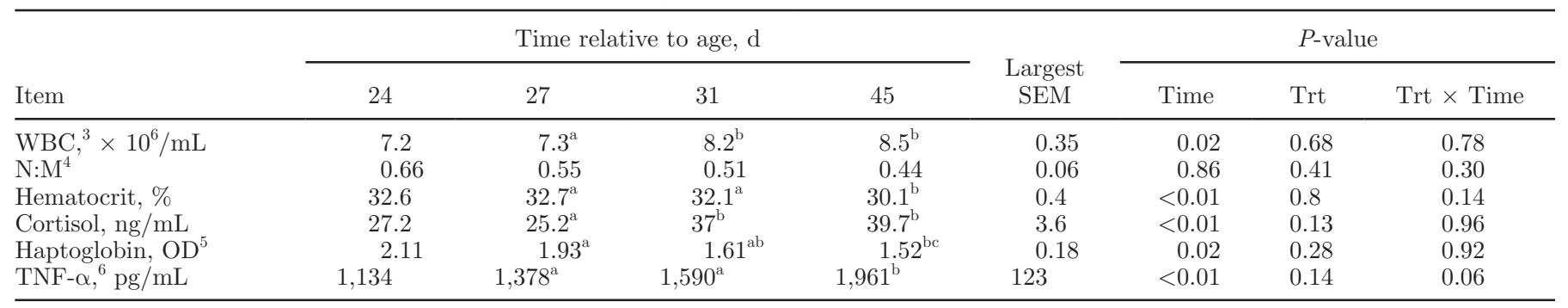

${ }^{\mathrm{a} c}$ Means within a row with different superscripts differ significantly, $P<0.05$.

${ }^{1}$ Calves were fed $227 \mathrm{~g}$ of milk replacer twice daily until $24 \pm 0.5 \mathrm{~d}$ of age. After $24 \mathrm{~d}$ of age, 22 calves (once-fed) had the evening milk feeding withdrawn and all $454 \mathrm{~g}$ of milk replacer was fed in the morning, whereas twice-fed calves $(\mathrm{n}=20)$ had no change in feeding strategy.

${ }^{2}$ Data for $24 \mathrm{~d}$ of age was used as a covariate in the model; therefore, comparisons between LS means were only made for d 27,31 , and 45 of age. Trt $=$ treatment.

${ }^{3}$ Circulating total leukocyte counts.

${ }^{4}$ Neutrophil:mononuclear ratios in peripheral blood; log-transformed $P$-values.

${ }^{5}$ Optical density $(\times 100)$; root-transformed $P$-values.

${ }^{6}$ Whole blood was stimulated with $1 \mu \mathrm{g} / \mathrm{mL}$ of LPS for $24 \mathrm{~h}$ and the supernatant was analyzed for tumor necrosis factor- $\alpha$ (TNF- $\alpha$ ). 
Table 4. Neutrophil means of blood measurements of once-fed calves after they had milk replacer consolidated into one feeding ${ }^{1,2}$

\begin{tabular}{lrrrrrr}
\hline & \multicolumn{5}{c}{ Time relative to age, d } & Largest \\
\cline { 2 - 5 } Item & \multicolumn{1}{c}{24} & \multicolumn{1}{c}{27} & \multicolumn{1}{c}{31} & 45 & SEM & $P$-value \\
\hline L-selectin, GMFI $^{3}$ & 76.4 & 76.3 & 105.8 & 105.8 & 16.8 & 0.07 \\
$\beta_{2}$-integrin, GMFI & 83.7 & 96.1 & 102.8 & 92.3 & 8 & 0.67 \\
OB+PG+, \% $^{4}$ & 101.7 & 102.5 & 100.8 & 102.2 & 1.9 & 0.17 \\
OB, GMFI $^{5}$ & 102.9 & 94.1 & 100.4 & 102.5 & 4.2 & 0.18 \\
PG, GMFI & 107.3 & 109.9 & 104.5 & 114.3 & 3.5 & 0.06 \\
\hline
\end{tabular}

${ }^{1}$ All flow cytometric measures are presented as a percentage of twice-fed calf day and block means.

${ }^{2}$ After $24 \mathrm{~d}$ of age samples were taken, once-fed calves had evening milk replacer feeding consolidated into one morning feeding. Age $24 \mathrm{~d}$ served as a covariate in the model.

${ }^{3}$ Geometric mean fluorescence intensity.

${ }^{4}$ Percentage of total neutrophils that produced both oxidative burst (OB) and phagocytosis (PG).

${ }^{5}$ Originally measured as GMFI; presented as log-transformed $P$-values.

treatments. Once-fed calves consumed similar amounts of starter as twice-fed calves, and it took less than $3 \mathrm{~d}$ to completely wean all calves from milk replacer. Therefore, weaning was a similar experience for all calves and was an abrupt weaning from milk replacer.

Three days after milk replacer was consolidated into one feeding for once-fed calves, their $\mathrm{N}: \mathrm{M}$ cell ratios tended to be greater than those for twice-fed calves. Total leukocytes counts did not suggest that the change in the ratio was a result of infection. Once-fed calves likely experienced an acute stress, as peripheral neutrophilia is commonly observed in cattle following many types of

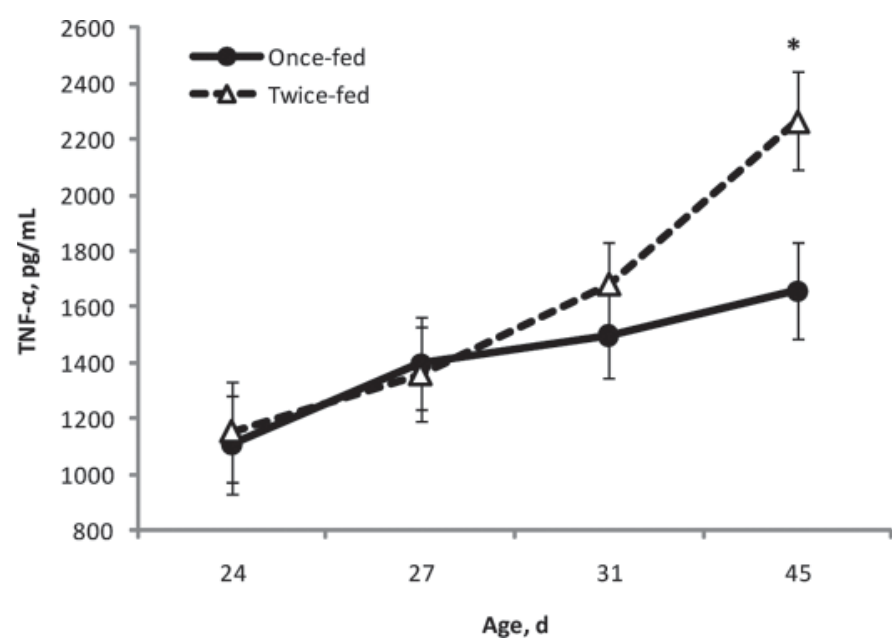

Figure 2. Acute effects on change in feeding frequency for tumor necrosis factor (TNF)- $\alpha$ secreted from LPS-stimulated whole blood for twice-fed and once-fed calves from 24 to $45 \mathrm{~d}$ of age. Treatment $\times$ time sliced effect $\log$-transformed ${ }^{*} P<0.05$. Calves were fed $227 \mathrm{~g}$ of milk replacer twice daily until $24 \pm 0.5 \mathrm{~d}$ of age. After $24 \mathrm{~d}$ of age, 22 calves (once-fed) had the evening milk feeding withdrawn and all $454 \mathrm{~g}$ of milk replacer was fed in the morning, whereas twice-fed calves $(\mathrm{n}=$ 20) had no change in feeding strategy. Whole blood was stimulated at a final concentration of $1 \mu \mathrm{g} / \mathrm{mL}$ of LPS for $24 \mathrm{~h}$ and the supernatant fraction was analyzed for TNF- $\alpha$. stressors (Murata et al., 1987; Buckham Sporer et al., 2007; Gupta et al., 2007). In addition, increased N:M ratios are commonly observed immediately following weaning stress (Hulbert et al., 2011). Furthermore, a transient increase in $\mathrm{N}: \mathrm{M}$ was also observed among all calves when they were weaned in the current study.

In addition to changes in circulating leukocyte proportions, functional capacities of neutrophils are responsive to stress, including suppression in phagocytic and oxidative burst capacities, as well as adhesion molecule expression (Burton et al., 2005; Buckham Sporer et al., 2007). However, the type and intensity of the stressor likely plays a role in the effect it has on the functional response of neutrophils (Sorrells and Sapolsky, 2007). The change in feeding frequency during the fourth week of life did not have an effect on neutrophil phagocytic or oxidative burst responses to $E$. coli, which suggests that the stress associated with the change in feeding frequency was either acute or less intense than other stressors. Pang et al. (2009) observed no changes in neutrophil phagocytic or oxidative burst capacities when Holstein bull calves were acutely challenged with hydrocortisone. Furthermore, no change in neutrophil phagocytic or oxidative burst capacities were observed when Holstein bull calves were castrated (Pang et al., 2009). These data suggest that acute stress might not impair neutrophil phagocytic and oxidative burst capacities. In contrast, exposing 5-wk-old Holstein calves to exercise and cold stress (Henricks et al., 1987) or weaning Holstein (Hulbert et al., 2011) and beef (Lynch et al., 2010) calves caused a transient decrease in the phagocytic and oxidative burst capacities of neutrophils. Once-fed calves were able to cope with the change in feeding frequency rather rapidly as evident by a lack of suppression of neutrophil phagocytic and oxidative burst capacities $3 \mathrm{~d}$ after consolidating to once-a-day feeding. The lack of neutrophil L-selectin suppression further supports the finding that Holstein 
Table 5. Daily means of blood parameters of all calves $(n=42)$ after weaning ${ }^{1}$

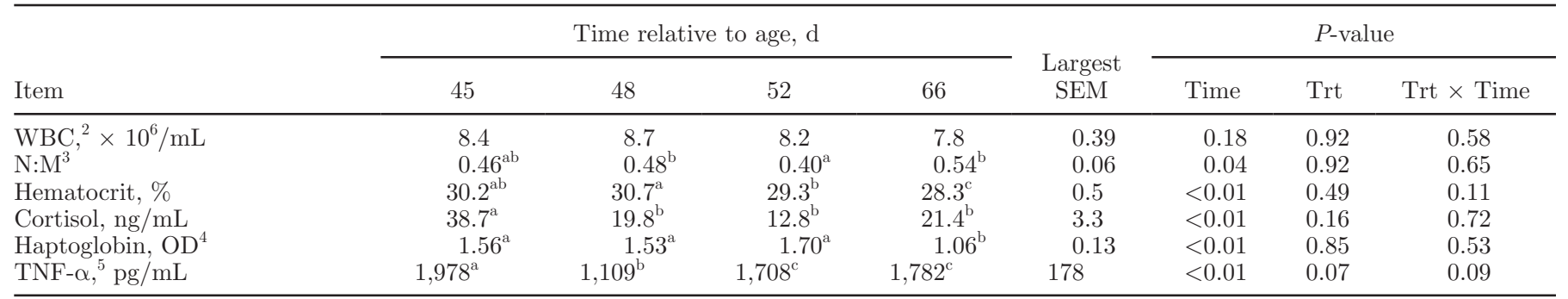

${ }^{\mathrm{a}-\mathrm{c}}$ Means within a row with different superscripts differ significantly, $P<0.05$.

${ }^{1}$ Calves were fed $227 \mathrm{~g}$ of milk replacer twice daily until $24 \pm 0.5 \mathrm{~d}$ of age. After $24 \mathrm{~d}$ of age, 22 calves (once-fed) had the evening milk feeding withdrawn and all $454 \mathrm{~g}$ of milk replacer was fed in the morning, whereas twice-fed calves $(\mathrm{n}=20)$ had no change in feeding strategy. Trt $=$ treatment.

${ }^{2}$ Circulating total leukocyte counts.

${ }^{3}$ Neutrophil:mononuclear ratios in peripheral blood; log-transformed $P$-values.

${ }^{4}$ Optical density $(\times 100)$; root-transformed $P$-values.

${ }^{5}$ Whole blood was stimulated with $1 \mu \mathrm{g} / \mathrm{mL}$ of LPS for $24 \mathrm{~h}$ and the supernatant was analyzed for tumor-necrosis factor- $\alpha$ (TNF- $\alpha$ ).

calves are able to cope rapidly with the change in feeding frequency during wk 4 of life. At 31 and $45 \mathrm{~d}$ of age, Once-fed calves actually expressed more L-selectin on their neutrophils. In a companion paper, Holstein calves weaned early had a transient decrease in Lselectin $3 \mathrm{~d}$ after initiating weaning, but compensated with greater expression $7 \mathrm{~d}$ after weaning (Hulbert et al., 2011). Additionally, when Holstein bull calves were transported, neutrophil L-selectin expression was decreased $4.5 \mathrm{~h}$ after transport; however, L-selectin expression was greater $9.75 \mathrm{~h}$ after transport than at baseline (Buckham Sporer et al., 2007). In contrast, neither intravenous challenge with hydrocortisone nor castration caused changes in neutrophil expression of L-selectin; however, parturition stress in Holstien cows caused a decreased neutrophil L-selectin expression (Weber et al., 2001). Collectively, these data suggest that mild or acute stressors do not, or only transiently, suppress neutrophil L-selectin expression and that neutrophils may be "primed" following this type of stress. Current data suggest that the mild stress of switching from twice-a-day feeding to once-a-day feeding during the fourth week of life stimulated neutrophil L-selectin expression. Further supporting that a mild stress increases expression of adhesion molecules on neutrophils is the observation that all calves had higher expression of $\beta_{2}$-integrin $3 \mathrm{~d}$ after weaning. The exact immunological significance of the elevated expression of an adhesion molecule following a mild stressor is not known, but this could be a compensatory mechanism that might improve resistance to disease.

At $45 \mathrm{~d}$ of age, which was $21 \mathrm{~d}$ after consolidating to a single feeding in the once-fed calves, secretion of TNF- $\alpha$ from whole blood cultures stimulated with LPS was decreased in the once-fed calves. Furthermore, during the postweaning period a tendency was observed for a carry-over effect, wherein once-fed calves continued to secrete less TNF- $\alpha$ from whole blood cultures. This response is not likely associated with the stressor of switching to once-a-day feeding because of the 21-d latency until the response was evident as well as its persistency into the postweaning period. In pigs, TNF- $\alpha$

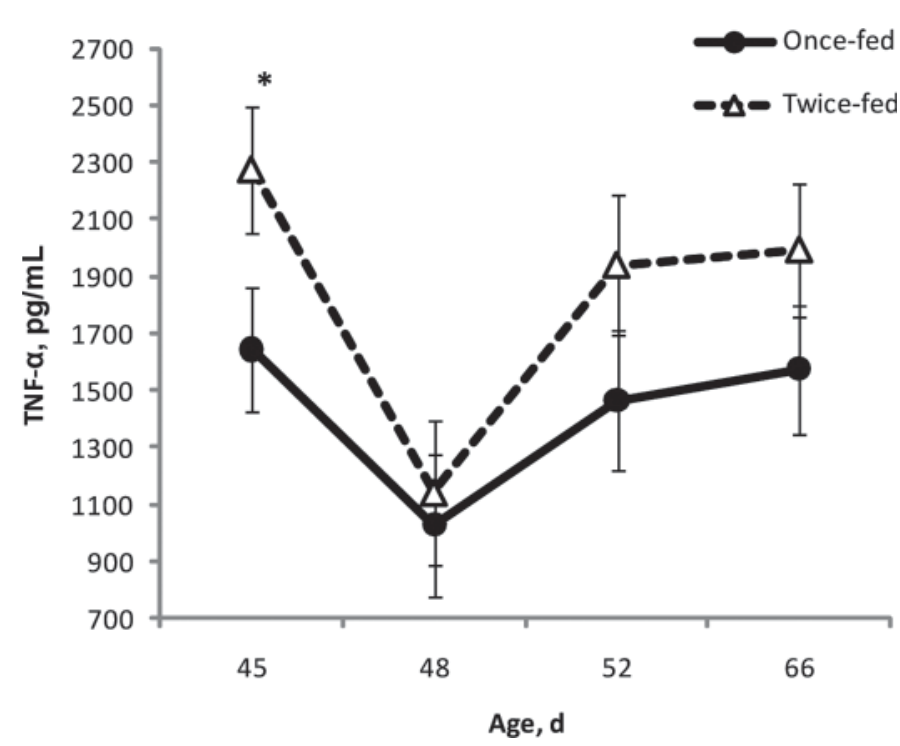

Figure 3. Weaning effects on calves fed milk replacer once or twice daily for tumor necrosis factor (TNF)- $\alpha$ secreted from LPS-stimulated whole blood from 45 to $66 \mathrm{~d}$ of age. Treatment $\times$ time sliced effect $\log$-transformed $* P<0.05$, and treatment effect $P=0.09$. Calves were fed $227 \mathrm{~g}$ of milk replacer twice daily until $24 \pm 0.5 \mathrm{~d}$ of age. After 24 $\mathrm{d}$ of age, 22 calves (once-fed) had the evening milk feeding withdrawn and all $454 \mathrm{~g}$ of milk replacer was fed in the morning, whereas twicefed calves $(\mathrm{n}=20)$ had no change in feeding strategy. Weaning was initiated by removing $50 \%$ of the milk replacer and then calves were completely weaned after consuming $900 \mathrm{~g}$ of as-fed calf starter for 2 consecutive days. Whole blood was stimulated at a final concentration of $1 \mu \mathrm{g} / \mathrm{mL}$ of LPS for $24 \mathrm{~h}$ and the supernatant fraction was analyzed for TNF- $\alpha$. 
Table 6. Neutrophil means of flow cytometry measurements of all calves after weaning ${ }^{1}$

\begin{tabular}{|c|c|c|c|c|c|c|c|c|}
\hline Item & \multicolumn{4}{|c|}{ Time relative to age, $\mathrm{d}$} & $\begin{array}{c}\text { Largest } \\
\text { SEM }\end{array}$ & \multicolumn{3}{|c|}{$P$-value } \\
\hline 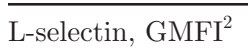 & 94.9 & 94 & 102.5 & 91.6 & 9.1 & 0.87 & 0.16 & 0.56 \\
\hline $\mathrm{OB}+\mathrm{PG}+, \%^{3}$ & $105.0^{\mathrm{a}}$ & $99.8^{\mathrm{b}}$ & $101.5^{\mathrm{c}}$ & $101.3^{\mathrm{c}}$ & 0.8 & $<0.01$ & 0.8 & 0.9 \\
\hline $\mathrm{OB}, \mathrm{GMFI}^{4}$ & $118.0^{\mathrm{a}}$ & $108.3^{\mathrm{b}}$ & $118.2^{\mathrm{c}}$ & $112.6^{\text {ac }}$ & 4.8 & 0.03 & 0.75 & 0.81 \\
\hline PG, GMFI ${ }^{4}$ & $112.6^{\mathrm{a}}$ & $98.9^{\mathrm{b}}$ & $112.2^{\mathrm{a}}$ & $101.2^{\mathrm{b}}$ & 3.8 & $<0.01$ & 0.21 & 0.61 \\
\hline
\end{tabular}

${ }^{\mathrm{a}-c}$ Means within a row with different superscripts differ significantly, $P<0.05$.

${ }^{1}$ All flow cytometric measures are presented as a percentage of control calf day and block means. Trt $=$ treatment.

${ }^{2}$ Geometric mean fluorescence intensity.

${ }^{3}$ Percentage of total neutrophils that produced both oxidative burst (OB) and phagocytosis (PG).

${ }^{4}$ Originally measured as GMFI; presented as log-transformed $P$-values.

secretion from whole blood cultures stimulated with LPS decreased by $61.7 \% 2 \mathrm{~d}$ after weaning (Carstensen et al., 2005). Lightweight, early-weaned Holstein bull calves had decreased secretion of TNF- $\alpha$ at 3 and 7 $\mathrm{d}$ after initiating weaning, but TNF- $\alpha$ concentrations returned to a level not different from that of nonweaned control calves by d 21 after weaning (Hulbert et al., 2011). In human surgical patients, low whole blood TNF- $\alpha$ responses were associated with greater morbidity and mortality (Heagy et al., 2003). The immunological significance of the lower TNF- $\alpha$ response by once-fed calves is not known, but it is conceivable that these calves may have decreased ability to activate an acute phase response and recruit effector cells to sites of infection. It is tempting to speculate on the mechanism underlying the lower secretion of TNF- $\alpha$ in once-fed calves. Early life experiences, either in utero or during the neonatal period, can influence a physiological response later in life. This phenomenon was coined "pre-programming" (Dörner, 1975). It is not known whether feeding frequency early in life can have persistent effects on the pro-inflammatory responsiveness of leukocytes to pathogen-associated molecular patterns; this warrants further research.

\section{CONCLUSIONS}

Consolidating calf milk replacer into one feeding during the fourth week of life was likely a mild and acute stressor as evident by transient neutrophilia in the absence of suppressed functional capacities of neutrophils. Once-fed calves did not have acute suppression of TNF- $\alpha$ secretion from whole blood cultures, but 21 $\mathrm{d}$ after changing the feeding frequency they were persistently lower through the end of the study. Whether this continues to persist later in life and the underlying mechanisms and resistance to disease implications of this are not known and warrant further research.

\section{ACKNOWLEDGMENTS}

The authors thank Jeff Dailey (USDA-ARS) and Colton Cobb (Texas Tech University) for their assistance with animal husbandry, Luke Schwertner (Texas Tech University) for his laboratory assistance, and Land O'Lakes Animal Milk Products Co. (Shoreview, MN) for donating milk replacer.

\section{REFERENCES}

Ackerman, R. A., R. O. Thomas, W. V. Thayne, and D. F. Butcher. 1969. Effects of once-a-day feeding of milk replacer on body weight gain of dairy calves. J. Dairy Sci. 52:1869-1872.

Arthington, J. D., S. D. Eicher, W. E. Kunkle, and F. G. Martin. 2003 Effect of transportation and commingling on the acute-phase protein response, growth, and feed intake of newly weaned beef calves. J. Anim. Sci. 81:1120-1125.

Ballou, M. A., and E. J. DePeters. 2008. Supplementing milk replacer with omega-3 fatty acids from fish oil on immunocompetence and health of Jersey calves. J. Dairy Sci. 91:3488-3500.

Buckham Sporer, K. R., J. L. Burton, B. Earley, and M. A. Crowe. 2007. Transportation stress in young bulls alters expression of neutrophil genes important for the regulation of apoptosis, tissue remodeling, margination, and anti-bacterial function. Vet. Immunol. Immunopathol. 118:19-29.

Burton, J. L., S. A. Madsen, L. C. Chang, P. S. Weber, K. R. Buckham, R. van Dorp, M. C. Hickey, and B. Earley. 2005. Gene expression signatures in neutrophils exposed to glucocorticoids: A new paradigm to help explain "neutrophil dysfunction" in parturient dairy cows. Vet. Immunol. Immunopathol. 105:197-219.

Carstensen, L., C. M. Røntved, and J. P. Nielsen. 2005. Determination of tumor necrosis factor-alpha responsiveness in piglets around weaning using an ex vivo whole blood stimulation assay. Vet. Immunol. Immunopathol. 105:59-66.

Dörner, G. 1975. Perinatal hormone levels and brain organization. Anat. Neuroendocrinol. 1:245-252.

Galton, D. M., and W. J. Brakel. 1976. Influence of feeding milk replacer once- versus twice- daily on growth, organ measurements, and mineral content of tissues. J. Dairy Sci. 59:944-948.

Gupta, S., B. Earley, and M. A. Crowe. 2007. Effect of 12-hour road transportation on physiological, immunological and haematological parameters in bulls housed at different space allowances. Vet. J. 173:605-616.

Heagy, W., K. Nieman, C. Hansen, M. Cohen, D. Danielson, and M. A. West. 2003. Lower levels of whole blood LPS-stimulated cytokine release are associated with poorer clinical outcomes in surgical ICU patients. Surg. Infect. (Larchmt) 4:171-180. 
Henricks, P. A. J., G. J. Binkhorst, and F. P. Nijkamp. 1987. Stress diminishes infiltration and oxygen metabolism of phagocytic cells in calves. Inflammation 11:427-437.

Hulbert, L. E., C. J. Cobb, J. A. Carroll, and M. A. Ballou. 2011. The effects of early weaning on innate immune responses of Holstein calves. J. Dairy Sci. 94:2545-2556.

Kehoe, S. I., C. D. Dechow, and A. J. Heinrichs. 2007. Effects of weaning age and milk feeding frequency on dairy calf growth, health and rumen parameters. Livest. Sci. 110:267-272.

Lynch, E. M., B. Earley, M. McGee, and S. Doyle. 2010. Effect of abrupt weaning at housing on leukocyte distribution, functional activity of neutrophils, and acute phase protein response of beef calves. BMC Vet. Res. 6:39-47.

Makimura, S., and N. Suzuki. 1982. Quantitative determination of bovine serum haptoglobin and its elevation in some inflammatory diseases. Nippon Juigaku Zasshi 44:15-21.
Murata, H., H. Takahashi, and H. Matsumoto. 1987. The effects of road transportation on peripheral blood lymphocyte subpopulations, lymphocyte blastogenesis and neutrophil function in calves. Br. Vet. J. 143:166-174.

Pang, W. Y., B. Earley, T. Sweeney, S. Pirani, V. Gath, and M. A. Crowe. 2009. Effects of banding or burdizzo castration of bulls on neutrophil phagocytosis and respiratory burst, CD62-L expression, and serum interleukin-8 concentration. J. Anim. Sci. 87:31873195.

Sorrells, S. F., and R. M. Sapolsky. 2007. An inflammatory review of glucocorticoid actions in the CNS. Brain Behav. Immunol. $21: 259-272$.

Weber, P. S., S. A. Madsen, G. W. Smith, J. J. Ireland, and J. L. Burton. 2001. Pre-translational regulation of neutrophil L-selectin in glucocorticoid-challenged cattle. Vet. Immunol. Immunopathol. 83:213-240. 